\title{
EUS-guided percutaneous endoscopic jejunostomy in cases not suitable for conventional gastrostomy: after bariatric (SADI-S) and cancer surgery
}

In a few cases, endoscopic ultrasound (EUS)-guided percutaneous endoscopic gastrostomy (PEG) has been reported as a safe alternative in cases that are not suitable for conventional PEG [1-3]. In the present case series, EUS-guided percutaneous endoscopic jejunostomy (PEJ) is offered as another option in scenarios with excessive distance from the stomach.

The first case was that of a 51-year-old man with amyotrophic lateral sclerosis with bulbar involvement who had undergone modified single-loop duodenal switch-type bariatric surgery (single duodenal-ileal bypass with sleeve gastrec- tomy, SADI-S) with subsequent conversion to Roux-en-Y. In the second case, a 70-year-old man with Ivor Lewis esophagectomy as an oncological treatment for esophageal cancer presented with a persistent tracheo-esophageal fistula. In both these patients, long-term enteral nutrition was required and lack of transillumination prevented conventional PEG placement. In a multidisciplinary team discussion, EUS-guided percutaneous placement of a feeding tube was proposed.

The technique was as follows. First, a percutaneous external "target" was created with a water-filled glove placed over the abdomen [3]. The next step was a first attempt to identify the EUS target from the stomach, but this failed because the distance was too great $(>5 \mathrm{~cm})$ despite hand pressure. The scope was then progressed to the proximal jejunum, from where the external EUS target was identified within an optimal therapeutic window (distance $<30 \mathrm{~mm}$, without vessel or small-bowel interposition). EUS-guided transjejunal puncture could now be performed using a 19-G needle and exerting hand pressure on the water-filled glove, until the needle tip emerged through the skin. A 0.025-inch guidewire was advanced, tied to the percutaneous feeding
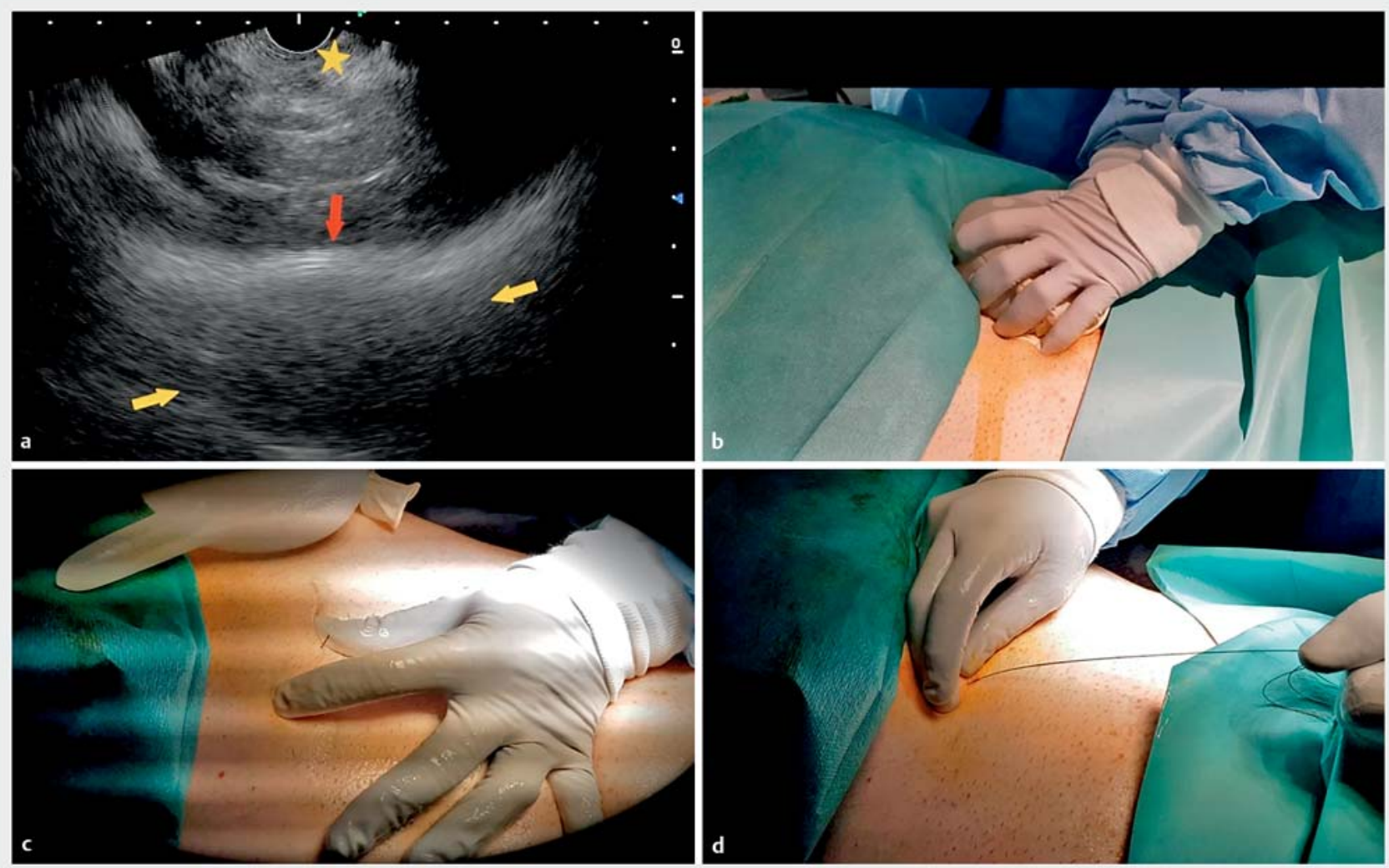

- Fig. 1 a, b Endoscopic ultrasound (EUS)-guided identification of the water-filled glove from the jejunum as an EUS target, through the application of hand pressure on the water-filled glove over the abdomen wall (yellow arrows, water-filled glove; red arrow, skin; yellow star, tip of EUS scope, located at the jejunum). c Needle tip passing through the skin, with a guidewire in place. $\mathbf{d}$ The guidewire is now across the small-bowel wall, having been previously advanced through a $19-G$ needle under EUS guidance. 




system introducer. Orifice enlargement was carried out with a scalpel to allow the tube to be introduced to the bowel as the guidewire was withdrawn through the mouth. Finally, the PEJ was placed by completing the usual steps with endoscopic confirmation that the jejunostomy position was correct ( $>$ Fig. 1; V Video 1 ). An intraprocedural pneumoperitoneum was managed conservatively. No other complications were reported, and enteral feeding was restarted without incident in both cases.

EUS-guided PEJ may be considered in cases where there are contraindications to endoscopic or radiological PEG placement due to surgical changes such as after bariatric (SADI-S type) or oncological procedures.

Endoscopy_UCTN_Code_TTT_1AO_2AK

\section{Competing interests}

J. B. Gornals is a consultant for Boston Scientific.
The authors

Sandra Maisterra ${ }^{1}$, Julio G. Velásquez-

Rodríguez ${ }^{1}$, Sandra Llauradó-Paco ${ }^{2}$, Ana

Casajoana-Badia ${ }^{3}$, Humberto Aranda ${ }^{4}$, Nuria

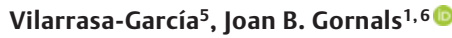

1 Endoscopy Unit, Digestive Diseases Department, Hospital Universitari de Bellvitge, Bellvitge Biomedical Research Institute (IDIBELL), University of Barcelona, Catalonia, Spain

2 Anesthesiology Department, Hospital Universitari de Bellvitge, Bellvitge Biomedical Research Institute (IDIBELL), University of Barcelona, Catalonia, Spain

3 Bariatric Surgery Unit, Hospital Universitari de Bellvitge, Bellvitge Biomedical Research Institute (IDIBELL), University of Barcelona, Catalonia, Spain

4 Esophagogastric Surgery Unit, General Surgery Department, Hospital Universitari de Bellvitge, Bellvitge Biomedical Research Institute (IDIBELL), University of Barcelona, Catalonia, Spain

5 Endocrinology and Clinical Nutrition Department, Hospital Universitari de Bellvitge, Bellvitge Biomedical Research Institute (IDIBELL), University of Barcelona, Catalonia, Spain

6 Faculty of Health Sciences, Universitat Oberta de Catalunya, Barcelona, Catalonia, Spain
Corresponding author

\section{Joan B. Gornals MD, PhD}

Endoscopy Unit, Department of Digestive Diseases, Hospital Universitari de Bellvitge, Feixa Llarga s/n, 08907 L'Hospitalet de Llobregat, Barcelona, Catalonia, Spain jgornals@bellvitgehospital.cat

References

[1] Chaves DM, Kumar A, Lera ME et al. EUSguided percutaneous endoscopic gastrostomy for enteral feeding tube placement. Gastrointest Endosc 2008; 68: 1168-1172

[2] Maurel ], Bertrand G, Beoletto F et al. Endoscopic ultrasound-guided gastrostomy to avoid interposed digestive loop is effective when lack of transillumination prevents percutaneous approach. Endoscopy 2020; 52: 402-403

[3] Baile-Maxía S, Medina-Prado L, Bozhychko M et al. Endoscopic ultrasound-guided percutaneous endoscopic gastrostomy. Dig Endosc 2020; 32: 984-988

\section{Bibliography}

Endoscopy 2022; 54: E92-E93

DOI 10.1055/a-1394-5762

ISSN 0013-726X

published online 15.3.2021

(C) 2021. Thieme. All rights reserved.

Georg Thieme Verlag KG, Rüdigerstraße 14, 70469 Stuttgart, Germany

\section{ENDOSCOPY E-VIDEOS \\ https://eref.thieme.de/e-videos}

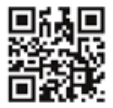

Endoscopy E-Videos is an open access online section, reporting on interesting cases and new techniques in gastroenterological endoscopy. All papers include a high quality video and all contributions are freely accessible online. Processing charges apply (currently EUR 375), discounts and wavers acc. to HINARI are available.

This section has its own submission website at https://mc.manuscriptcentral.com/e-videos 